\title{
Meta-analysis of Salt Valproate Prevent Switch Associated with Antidepressants in Chinese Depressive Patients
}

\author{
Dong Shen \\ Jiaxing Kangci Hospital \\ Wangqiang Lv \\ Jinhua Second Hospital \\ Fengli Sun \\ Zhejiang Province Mental Health Center \\ Jin Weidong ( $\nabla$ wdjin@163.com ) \\ Zhejiang Chinese Medical University
}

\section{Research Article}

Keywords: Salt valproate, Depressive patients, Switch rate

Posted Date: June 4th, 2021

DOI: https://doi.org/10.21203/rs.3.rs-538703/v1

License: (우 (i) This work is licensed under a Creative Commons Attribution 4.0 International License. Read Full License 


\section{Abstract}

Objective: to study the efficacy of valproate in preventing switch rate related to antidepressant in depressive patients.

Methods: The related literature were searched in Chinese Biomedical Database(CBM), China National Knowledge Infrastructure(CNKI), WANFANG database,and Chinese Social Sciences Citation Index(CSSCI) from 1 January 2005 to 1 January 2020 The rate of switch between groups was synthesized and discussed.

\section{Result:}

A total of 549 subjects were included in 7 studies,in which in 279 cases are in combination group and 270 cases are in group of monotherapy by antidepressant. The results showed switch rate of valproate group was $0.11 \%$,switch rate of antidepressant group was $11.11 \%$, which was very different (OR=0.13,95\% Cl: $0.05-0.35)$ and also indicated that valproate reduced switch rate was $99 \%[(11.11 \%-0.11 \%) / 11.11 \%]$. In sodium valproate group, switch rate was $0 \% \rrbracket$ while switch rate in antidepressant was $5.7 \%($ $\mathrm{OR}=0.18,95 \% \mathrm{Cl}=0.04-0.84, \mathrm{Z}=2.18, \mathrm{P}=0.03)$. In magnesium valproate group, switch rate was $2.2 \%$, while switch rate in antidepressant was $16.92 \%(\mathrm{OR}=0.11,95 \% \mathrm{Cl}=0.03-0.39, \mathrm{Z}=3.47, \mathrm{P}=0.0005)$.

Conclusion:The salt valproate can reduced switch rate related to antidepressant in depressive patients.

\section{Background}

Valproate may be applied to depression for the following reasons: First, in the study, as an important intensive treatment, it is used in the treatment of depression [1]. Second, valproate can improve the symptoms of refractory depression[2, 3]. Third, valproate is beneficial to the improvement of irritability, impulse and anxiety symptoms of irritable depression [4,5]. Fourth, valproate is widely used in post-stroke depression in China [6, 7].

In the consensus of experts on the psychiatric application of valproate, the prevention of manic conversion is also one of the important roles of valproate [8]. During the treatment ,manic symptoms may appear, which are related to antidepressant, patients were diagnosed as bipolar disorder $[9,10,11]$. In fact, one of the principles is to avoid turning manic as the treatment of bipolar depression [12]. However, since most bipolar disorder often starts with depression, which often treated with antidepressant and switch $[13,14]$.The lithium can prevent the switch and decrease the more $50 \%$ switch rate[15]. As valproate can improve the irritable,compulsive and mixed symptom in depression,so the avoidance of switch. This study just is a metaanalysis about prevention of switch by valproate.

\section{Methods}

\section{Literature retrieval methods:}


1.1 This study was performed according to the recommendations of the Moose [16] The database includes Chinese Biomedical Database (CBM), China National Knowledge Infrastructure (CNKI), WANFANG and Chinese Social Sciences Citation Index (VIP) databases .

1.2 Search key words and strategy: Depression (depression,depressive episode); salt valproate(sodium or magnesium).Last query was updated on late 1 January 2005 to 1 January 2020.

1.3 Two psychiatrists reviewed each included article independently, using the 11-item checklist that was recommended by the Agency for Healthcare Research and Quality (AHRQ) [16].

1.4 Statistic analysis:All statistical analyses were performed using Statistical Analysis System software (Revman 5.2), and the $P$ value for the overall effect $<0.05$ with two-tailed was considered statistically significant.

\section{Results}

\section{Study Characteristic}

7 comparison studies, with 549 subjects, met the inclusion criteria and were included for the final metaanalysis[17,18,19,20,21,22,23,],see table1.

2.Comparison of switch rate between experimental group and control group.

A total of 549 subjects were included in 7 studies. The results showed that the switch rate of salt valproate was $0.11 \%(3 / 279)$,switch rate of antidepressant was $11.11 \%(30 / 270)$, which was very different in switch rate(OR=0.13,95\% Cl: $0.05-0.35)$.The switch rate in experimental group was significantly lower than in that in control group $(Z=4.11, P<0.0001)$. And it also indicated that salt valproate reduced switch rate was $99 \%($ $11.11 \%-0.11 \% / 11.11 \%)$.See figure2.

The funnel plot analysis of study about switch rate show a gap,which indicate there maybe a bias of publication.see figure3.

3.Subgroup comparison of switch rate

Subgroup comparison of switch rate according to salt valproate,which conclude sodium and magnesium valproate. A total of 285 depressive subjects treated and compared by sodium valproate were included in 4 studies. The switch rate of sodium valproate group was $0.00 \%(0 / 145)$,switch rate of antidepressant group was $5.7 \% \%(8 / 140)$, which was very different in switch rate(OR=0.18,95\% Cl=0.04-0.84,Z=2.18, $\mathrm{P}=0.0033)$. The sodium valproate reduced switch rate was $100 \%$ (5.7\%-0\%/5.7\%). See figure4.

A total of 264 depressive subjects treated and compared by magnesium valproate were included in 3 studies. The switch rate of magnesium valproate group was $2.2 \%(3 / 134)$,switch rate of antidepressant group was $16.92 \%(22 / 130)$, which was very different in switch rate(OR=0.11,95\% Cl=0.03- 
$0.39, \mathrm{Z}=3.47, \mathrm{P}=0.0005)$. The magnesium valproate reduced switch rate was $98.7 \%(16.22 \%-2.2 \% / 16.22 \%)$. See figure4.

\section{Discussion}

The salt valproate primarily was used for bipolar disorder. Just according to type of depressive episode,salt valproate more was used in treatment bipolar depression[24,25],In a study, lurasidone adjunctive with lithium or valproate demonstrated significant improvement in depressive symptoms based on the MADRS from weeks $2-5$ but not at the primary week 6 endpoint[25].Meta-analysis showed a significant difference in favour of valproate for reduction in depressive symptoms, both on depression symptom scales (standardized mean difference (SMD) -0.35 (95\% confidence interval, $-0.69,-0.02)$ ), and participants with at least $50 \%$ improvement in symptoms - relative risk (RR) $2.00(1.13,3.53)[24]$.

But valproate also was used for other type depression,such as $\operatorname{TRD}[2,3]$,depression with mixed future,with agitated or anxiety symptoms[26,27].It also hint valproate maybe effective in prevention of switch associated with antidepressant.In fact,the risk of switch associated with antidepressant in patients with depression was monotherapy by antidepressant and without use of mood stabilizer[12].

In this study,valproate can decrease the possibility of switch associated with antidepressant. The switch rate in experimental group was significantly lower than in that in control group $(Z=2.18 \sim 3.47, P=0.0033 \sim$ $0.0005, \mathrm{OR}=0.11-0.18)$. In total,the results showed that the switch rate of salt valproate was $0.11 \%$ (3/279), switch rate of antidepressant was $11.11 \%(30 / 270)$, which was very different in switch rate(OR = $0.13,95 \% \mathrm{Cl}: 0.05-0.35, \mathrm{Z}=4.11, \mathrm{P}<0.0001)$. And it also indicated that salt valproate reduced switch rate was $99 \%(11.11 \%-0.11 \% / 11.11 \%)$.So we need cautiously regard this results that salt valproate decrease the switch rate induced by antidepressant during treatment for patients with depression.

The certain number of depressive patients switch to mania or exciting status during treatment by antidepressant,of which could be diagnosed by criteria of bipolar disorder in DSM-5[28 ].But this is not successful therapeutic plan for patient duo to switch,because it induce the mania ahead[29].So avoiding switch to mania is important part of therapeutic plan,whereas the patients is unipolar or bipolar depression.

The switch-inducing potential of antidepressants is unclear, which can trigger mood episode switches in patients with bipolar disorder or soft bipolar disorder[30].

This study had several limitations. Firstly, the sample size of this meta-analysis was relatively small. Only 7 studies and 549 subjects were involved. Secondly, collecting data style may influence the result of

investigation, for example,different criteria of switch can get different detection rate of switch. so it was very import to establish a diagnostic criteria for switch associated with antidepressant.Thirdly, not all the studies had blind observation. These factors are partly responsible for the source of pool rate of switch associated with antidepressant, also affect us to see the real significance and risk of switch.

\section{Conclusion}


As mood stabilizer,the both sodium valproate and magnesium valproate can reduced switch rate related to antidepressant in depressive patients. The salt valproate can reduced switch rate was $99 \%$.

\section{Declarations}

\section{Ethics approval and consent to participate}

Not Available

\section{Consent to publication}

All authors agree to publish our paper and no conflict in any interests.

\section{Availability of data and material.}

See Table1

\section{Competing interests}

There were not any financial and non-financial competing interests.

\section{Funding}

Not Available

\section{Authou's contribution}

All authors have read and approved the manuscript

Our authors have different contributions to this article. Dr SD participated in collection of data and the writing of the article, Dr SD,Dr ZY and Dr LY assessed the quality of researched papers. Dr LJ complete most statistic analysis.All authors reviewed researched whole paper. Prof JWD participated in the design , statistical processing and the final revision of the article.

\section{Acknowledgment}

We thank Mr Xv Songquan give us study idea and Mr Wang Zhiqiang help us in literature retrieval. We thank Ms Ren xin help us in part of statistic.We thanks Prof Ma Yongchun in final revision of the article.

\section{References}

1. Rush, J.A.,Warden, D.,Wisniewski, S.R.,Fava, M.,Trivedi, M.H.,Gaynes, B.N.,Nierenberg, A.A. . STAR*D: Revising conventional wisdom. CNS Drugs,2009; 23 (8) : 627-647. https://doi.org/10.2165/00023210200923080-00001

2. Maykel F Ghabrash , Stefano Comai , John Tabaka , Marie Saint-Laurent , Linda Booij , Gabriella Gobbi. Valproate augmentation in a subgroup of patients with treatment-resistant unipolar 
depression.World J Biol Psychiatry. 2016;17(2):165-70. doi: 10.3109/15622975.2015.1073856.

3. Chen Fengpei, Zhu jianfeng, Gao Zhihan, Jin Rui, Ren Zhibin, Chen Zhenxin, Ma Yongchun, Jin weidong. The Role of the Magnesium Valproate in Therapy for Patients with Treatment- Resistant Depression (TRD):meta-analysis Results of Chinese Data. International Journal Of Pharmacy and Chemistry,2018,4(3):23-30. doi:10.11648/j.ijpc.20180403.11.

4. Akiskal HS, Benazzi F, Perugi G, Rihmer Z. Agitated "unipolar" depression re-conceptualized as a depressive mixed state: implications for the antidepressant-suicide controversy.J Affect Disord. 2005 ;85(3):245-58. doi: 10.1016/j.jad.2004.12.004.

5. Ma Yanbing Guo Yaming.Clinical observation of magnesium valproate sustained release tablets and sodium valproate in the treatment of anxiety and depression China Prac Med . 2016 ;11(8):1271299.doi:10.14163/j.cnki.11-5547/r.2016.08.092

6. Xu Lili, Wang Yunpu, Wang Na, Ding Li. Clinical effects of magnesium valproate sustained-release tables combined with paroxetine on patients with post-stroke depression.China Medicine,2017,12(5):746-750. doi:10.3760/cna.j.issn.1673-4777.2017.05.026

7. Sun Yang, Zhu Xiaobo, Jin Weiwei, Gao Xianfeng, liu Jingwei, Wang Wei. Clinical effect of magnesium valproate sustained release table combined with paroxetine in treating elderly patients with poststroke depression. Practical Journal Of Cardiac Cerebral Pneumal and Vascular Disease.2016,24(6):100-103. doi:10.3969/j.issn.1008-5971.2016.06.026

8. Jin Weidong, Tan Qingrong, Zhang Ning,Li Lingjiang, Xu Yifeng, Hao Wei, Guo Tiansheng, Miao Guodong, Liu Tiebang, Fang Yiru, Jia Fujun, Li Jing, Wang Bo, Lv Luxian.The expert consensus about magnesium valproate sustained release table in treatment for bipolar disorder.Journal of Clinical Psychiatry $₫ 2012,22(5) \llbracket 289-292 \rrbracket$ doi $₫ C N K I: S U N: L C J S .0 .2012-05-003$

9. Wen Lu, Li Bingling, Ma Yongchun, Chen Jiong and Jin Weidong. Prospective observation of switching rate of antidepressants in management of depressive episode in 3 months. Sichuan Mental Health, 2015,28(1):1-3. doi:10.11886/j.issn.1007-3256.2015.01.001

10. Elie Cheniaux , Antonio E Nardi.Evaluating the efficacy and safety of antidepressants in patients with bipolar disorder.Expert Opin Drug Saf. 2019 ;18(10):893-913. doi: 10.1080/14740338.2019.1651291.

11. Kaltenboeck A, Winkler D, Kasper S.Bipolar and related disorders in DSM-5 and ICD-10.CNS Spectr. 2016 ;21(4):318-23. doi: 10.1017/S1092852916000079.

12. Gao Zhihan, Jin Weidong.Antidepressants and switch.Sichuan Mental Health.2015,28(1):1416,doi:10.11886/j.issn.1007-3256.2015.01.005

13. Alloy LB, Boland EM, Ng TH, Whitehouse WG, Abramson LY.Low social rhythm regularity predicts first onset of bipolar spectrum disorders among at-risk individuals with reward hypersensitivity.J Abnorm Psychol. 2015 ;124(4):944-952. doi: 10.1037/abn0000107.

14. Su Zongrong, Jin Weidong.On breakthrough episode.Shangdong Archives of Psychiatry,2002,1:5961.CNKI:SUN:SDJB.0.2002-01-038

15. Jin Xueguang, Jin Weidong.Lithium carbnate reduce the switc rate induced by antidepressant:metaananlysis of domestic data.Arch of Shanghai Psychiatry, 2007,19(5):313-314.doi:10.3969/jissn.10020829.2007.05.018 
16. Celiac Disease. Rockville: Agency for Healthcare Research and Quality (US); 2004.

[https://www.ncbi.nlm.nih.gov/books/NBK35149/].

17. Xie Jianping, Ren Zhibin,Ma Yongchun, Tang Jianliang, Jin Weidong.Comparing study on therapeutic of outpatients with agitated or anxiety depression by combination of SSRI and sodium valproate RX Chinese Journal of Clinical Pharmacology and Therapeutics.2013凶18(1)凶86-89

18. Qian Mincai , Shen Xinhua,Niu Furong, Sun Jushui, Zhu Yiping, Wang Chunsheng, Yang Jianhong, Lin Min. The efficacy of mood stabilizer for prevention of switch to mania in the first

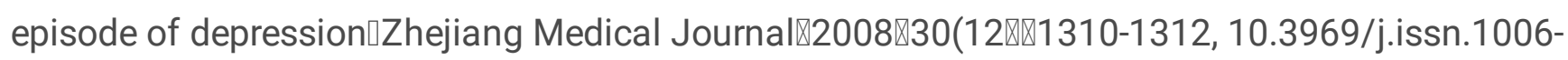
2785.2008.12.012

19. Wang Xiaozhen.The observation of effect in preventing switch of mood stabilizes in patients with depression. China Health Care and Nutrition, 2014,6:3450-3451, doi:10.3969/j.issn.10047484(x).2014.06.534

20. Feng Zhengmin,Liu Bo.Observation on Clinical Curative Effect of Paroxetine Combined with Magnesium Valproate Sustained Release Tablets in Treatment of Depression,China Journal of Health Psychology.2011,19(1):6-7.

21. Yang Yang, Zhao Haining, Zhu Yan.Adjuctive Therapeutic Effect of Valproate on Comorbid Anxiety and Depression,China Modern Doctor,2008,46(36):91-92, doi囚10.3969/j.issn.1673-9701.2008.36.050

22. Yu Caixia, Ji Decai, Huang Qing.Comparative study of paroxetine combing with sodium valproate in treatment depressive patients with anxiety symptoms.China Practice Medicine,2008,3(24):130-131 Doi:10.3969/j.issn.1673-7555.2008.24.093

23. Zhou Borong, Deng Yanhua, Xiao Yuqing,Xu Zhiqiang.A Controlled Study on Combination of Sodium Valproate with Paroxetine in the Treatment of Depressive Disorders with Anxiety Symptoms.Chinese Mental Health Journal. 2005,19(10):716-717,doi:10.3321/j.issn:1000-6729.2005.10.028

24. L A Smith, V R Cornelius, J M Azorin, G Perugi, E Vieta, A H Young, C L Bowden.Valproate for the treatment of acute bipolar depression: systematic review and meta-analysis.J Affect Disord. 2010 ;122(1-2):1-9. doi: 10.1016/j.jad.2009.10.033.

25. Trisha Suppes , Hans Kroger , Andrei Pikalov , Antony Loebel.Lurasidone adjunctive with lithium or valproate for bipolar depression: A placebo-controlled trial utilizing prospective and retrospective enrolment cohorts.Psychiatr Res. 2016 ;78:86-93. doi: 10.1016/j.jpsychires.2016.03.012.

26. Debattista C, Solomon A, Arnow B, Kendrick E, Tilston J, Schatzberg AF.The efficacy of divalproex sodium in the treatment of agitation associated with major depression. J Clin Psychopharmacol. 2005 ;25(5):476-9. doi: 10.1097/01.jcp.0000177552.21338.b0.

27. Daniel V Vigo, Ross J Baldessarini.Anticonvulsants in the treatment of major depressive disorder: an overview.Harv Rev Psychiatry. 2009;17(4):231-41. doi: 10.1080/10673220903129814.

28. de Dios C, Goikolea JM, Colom F, Moreno C, Vieta E.Bipolar disorders in the new DSM-5 and ICD-11 classifications.Rev Psiquiatr Salud Ment. 2014;7(4):179-85. doi: 10.1016/j.rpsm.2014.07.005.

29. Jin Weidong, Tang Jianliang. Bipolar Mood Disorder,People`s Millitary Medical Press,First edtion,2011 30. Giacomo Salvadore, Jorge A Quiroz, Rodrigo Machado-Vieira, Ioline D Henter, Husseini K Manji, Carlos A Zarate Jr.The neurobiology of the switch process in bipolar disorder: a review.J Clin Psychiatry. 2010 
;71(11):1488-501. doi: 10.4088/JCP.09r05259gre.

\section{Tables}

Table1: Characteristics of studies included in the meta-analysis

\begin{tabular}{|llllllll|}
\hline Author(year) & $\begin{array}{l}\text { Study } \\
\text { design }\end{array}$ & $\begin{array}{l}\text { Experimental } \\
\text { group(EG) } \\
\text { cases }\end{array}$ & $\begin{array}{l}\text { Cases } \\
\text { of } \\
\text { switch } \\
\text { in EG }\end{array}$ & $\begin{array}{l}\text { Control } \\
\text { group(CG) } \\
\text { cases }\end{array}$ & $\begin{array}{l}\text { Cases } \\
\text { of } \\
\text { switch } \\
\text { in CG }\end{array}$ & $\begin{array}{l}\text { Quality } \\
\text { score }\end{array}$ & $\begin{array}{l}\text { Salt } \\
\text { Valproate }\end{array}$ \\
\hline Feng(2001) & Comparison & 50 & 1 & 50 & 8 & 8 & Sodium \\
\hline Qian(2008) & Comparison & 49 & 1 & 45 & 8 & 8 & Sodium \\
\hline Wang(2014) & Comparison & 35 & 1 & 35 & 6 & 8 & Sodium \\
\hline Xie(2013) & Comparison & 40 & 0 & 40 & 1 & 8 & Magnesium \\
\hline Yang(2008) & Comparison & 35 & 0 & 30 & 2 & 8 & Magnesium \\
\hline Yu(2008) & Comparison & 40 & 0 & 40 & 3 & 8 & Magnesium \\
\hline Zhou(2005) & Comparison & 30 & 0 & 30 & 2 & 8 & Magnesium \\
\hline
\end{tabular}

\section{Figures}




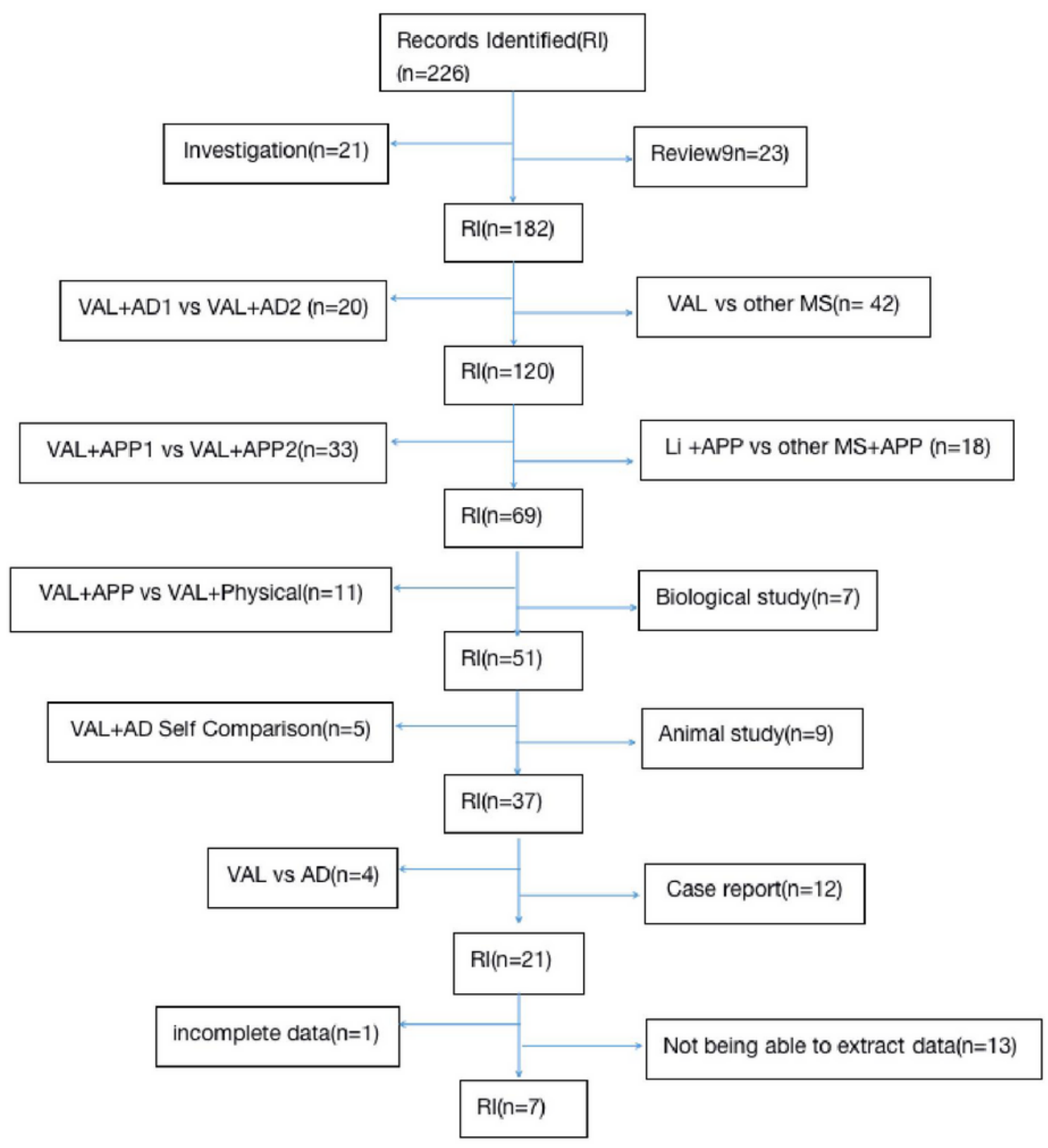

Figure 1

Search process VAL=Salt Valproate; $A D=$ Antidepressants; $A P P=A$ typical antipychotic; $M S=$ Mood Stabilizer 


\begin{tabular}{|c|c|c|c|c|c|c|c|c|c|}
\hline \multirow[b]{2}{*}{ Study or Subgroup } & \multicolumn{2}{|c|}{ Experimental } & \multicolumn{2}{|c|}{ Control } & \multirow{2}{*}{\multicolumn{2}{|c|}{$\begin{array}{c}\text { Odds Ratio } \\
\text { Weight } \mathrm{M}-\mathrm{H}, \text { Fixed, } 95 \% \mathrm{Cl}\end{array}$}} & \multirow{2}{*}{\multicolumn{3}{|c|}{$\begin{array}{c}\text { Odds Ratio } \\
\text { M-H, Fixed, } 95 \% \mathrm{Cl}\end{array}$}} \\
\hline & Events & Total & Events & Total & & & & & \\
\hline Feng (2011) & 1 & 50 & 8 & 50 & $24.6 \%$ & $0.11[0.01,0.89]$ & 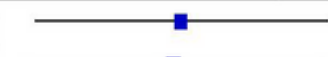 & & \\
\hline Qian (2008) & 1 & 49 & 8 & 45 & $25.6 \%$ & $0.10[0.01,0.80]$ & & & \\
\hline Wang (2014) & 1 & 35 & 6 & 35 & $18.3 \%$ & $0.14[0.02,1.25]$ & & & \\
\hline Xie (2013 & 0 & 40 & 1 & 40 & $4.6 \%$ & $0.33[0.01,8.22]$ & & & \\
\hline Yang (2008) & 0 & 35 & 2 & 30 & $8.3 \%$ & $0.16[0.01,3.48]$ & & & \\
\hline$Y u(2008)$ & 0 & 40 & 3 & 40 & $10.8 \%$ & $0.13[0.01,2.65]$ & & & \\
\hline Zhou (2005) & 0 & 30 & 2 & 30 & $7.7 \%$ & $0.19[0.01,4.06]$ & & & \\
\hline Total $(95 \% \mathrm{Cl})$ & & 279 & & 270 & $100.0 \%$ & $0.13[0.05,0.35]$ & & & \\
\hline Total events & 3 & & 30 & & & & & & \\
\hline $\begin{array}{l}\text { Heterogeneity. Chi } \\
\text { Test for }\end{array}$ & $\begin{array}{l}0.49, d f= \\
7=411\end{array}$ & $\begin{array}{l}6(P=1.0 \\
6<0.000\end{array}$ & $00) ; 1^{2}=0$ & & & & 0.01 & 1 & $100^{\circ}$ \\
\hline
\end{tabular}

\section{Figure 2}

Comparison of switch rate between experimental group and control group. The fixed random model was used. The results showed that the switch rate of salt valproate was $0.11 \%(3 / 279)$, switch rate of antidepressant was $11.11 \%(30 / 270)$, which was very different in switch rate(OR=0.13, 95\% Cl: 0.05-0.35). The switch rate in experimental group was significantly lower than in that in control group $(Z=4.11, P<0.0001)$.

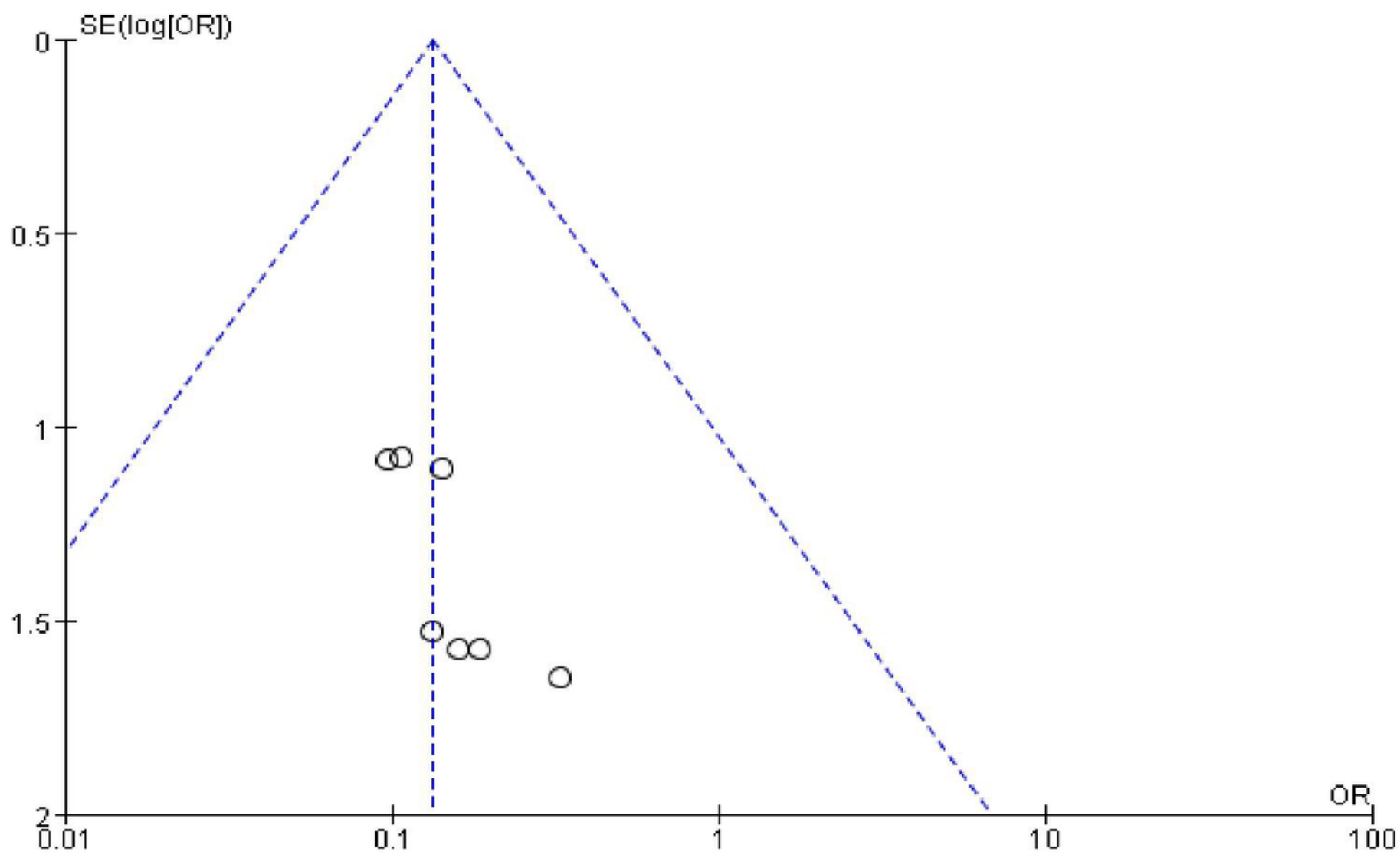


Figure 3

The funnel plot analysis of study about switch rate. switch rate show a gap, which indicate there maybe a bias of publication.

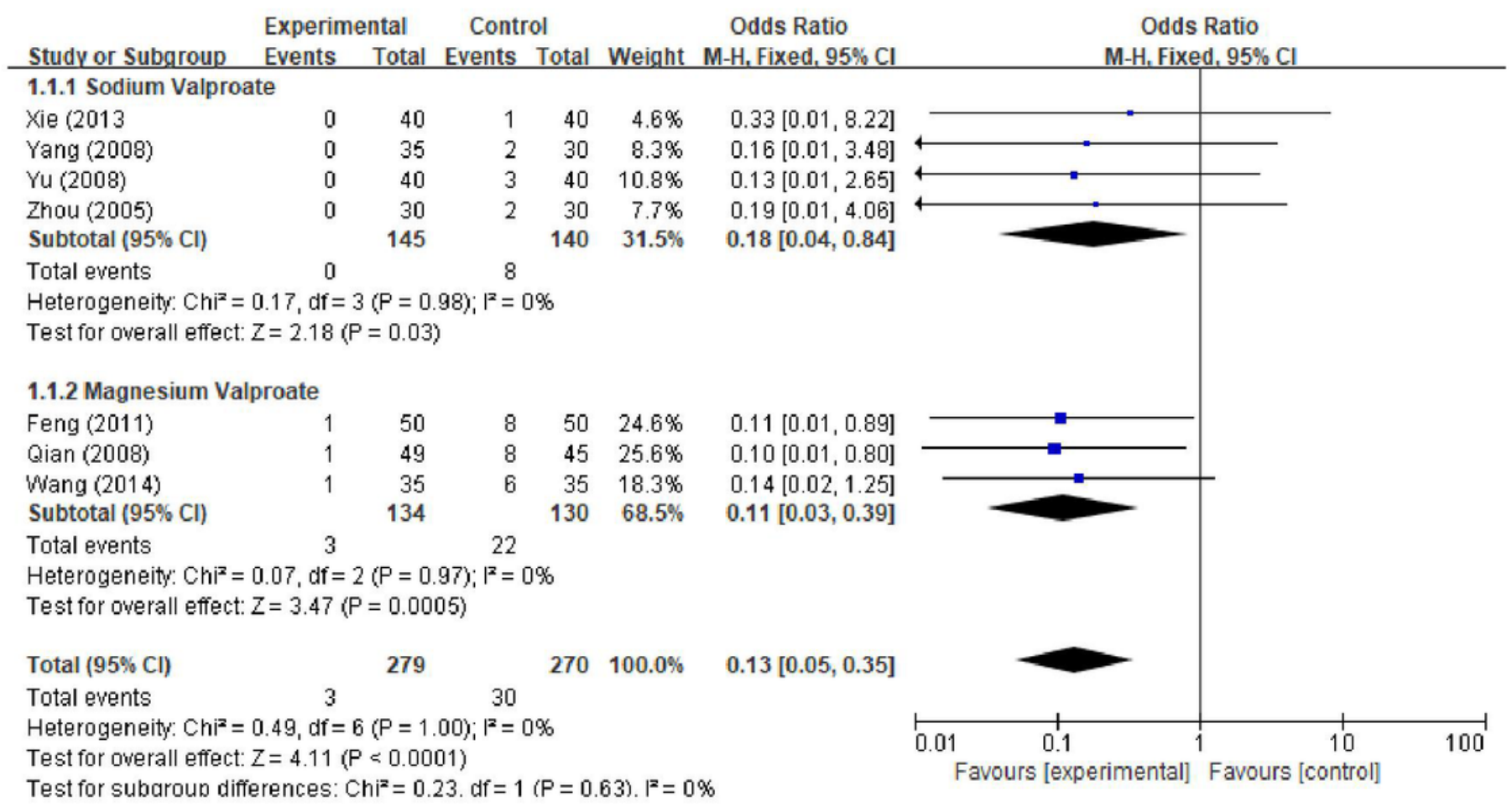

\section{Figure 4}

Subgroup comparison of switch rate according to salt valproate. The fixed random model was used. The switch rate of sodium valproate group was $0.00 \%(0 / 145)$, switch rate of antidepressant group was $5.7 \% \%$ (8/140), which was very different in switch rate(OR=0.18, 95\% $\mathrm{Cl}=0.04-0.84)$. The switch rate in experimental group was significantly lower than in that in control group $(Z=2.18, P=0.0033)$. he switch rate of magnesium valproate group was $2.2 \%(3 / 134)$, switch rate of antidepressant group was $16.92 \%(22 / 130)$, which was very different in switch rate $(\mathrm{OR}=0.11,95 \% \mathrm{Cl}=0.03-0.39)$. The switch rate in experimental group was significantly lower than in that in control group $(Z=3.47, P=0.0005)$ 